\title{
Dynamic response of a structure due to different vibration sources
}

\author{
Janusz P. Kogut ${ }^{1, *}$, and Tomasz Śmierciak ${ }^{1}$ \\ ${ }^{1}$ Cracow University of Technology, Faculty of Civil Engineering, Kraków, Poland
}

\begin{abstract}
The aim of the work is to acquire the answer for a question if, and to what extent the dynamic excitation forced by underground movement of metro carts or another vibration source impacts the condition of the existing building. To get that assessment, a corresponding numerical model of the tunnel and soil and the structure is created. As input, the acceleration response spectrum computed for the Gulf of Aquaba earthquake is used, as well as the quasi-static axle loading of typical metro carts. The output is shown as the time-history response of the ground-level nodes that will later be used to assess the influence of vibrations with the help of Ciesielski (SWD) scales.
\end{abstract}

Keywords: non-cohesive soils, vibrations propagation, numerical model

\section{Introduction}

Construction of new metro lines, as well as the exploatation of existing ones may have undesirable effects on the condition of nearby buildings and infrastructure. Vibrations caused by the construction works and movement of metro carts lead to kinematic excitation of a structure. Such movement of building components results in additional forces which existing building may not have been designed to bear. The outcome of that could be increased wear, cracks or even local destruction of elements and danger to people. One instance of a building like that is a property located in Great Cairo, Egypt at Nazih Khalifa street of Heliopolis. It was erected around year 1920 and is at the time the office of Polish Centre of Mediterranean Archeology of the University of Warsaw. The centre was established sixty years ago, and at the occasion of that fact, this paper is written.

The plot on which the building is built lies in the seismic area and was subjected to multiple earthquakes like Gulf of Aquaba earthquake in 1995, or Cairo earthquake in 1992 and many microquakes noted in the area [1]. There were several construction works conducted in the vicinity of the building: erection of a multi-level buildings and the metro station. Phase 2 of Cairo Metro Line 3 was finished in May 2014 and the metro trains run under Nazih Khalifa,

\footnotetext{
*Corresponding author: jkogut@pk.edu.pl
} 
approximately 30 meters under ground level and 40 meters from the building, where the AlAhram station is located. Cairo metro operates 20 hours a day, thanks to that, the building is subjected to nearly constant vibrations propagating through the ground. There were already cracks visible throughout the building that have widened after the construction works in the area. Due to problems with water leakages and corrosion of steel sections on which the slabs are supported, additional dynamic forces originating either from metro line or another earthquake may even lead to the destruction of the constructional elements of the house.

\section{Numerical models}

The aim of the work is to acquire the answer for a question if, and to what extent the dynamic excitation forced by underground movement of metro carts or another earthquake impacts the condition of building. To get that assessment, a corresponding numerical model is created. As the input, the data about the acceleration spectrum collected from Gulf of Aquaba earthquake is used, as well as the axle load and distance of typical metro carts. Figure 1 presents acceleration response spectrum computed for the Gulf of Aquaba earthquake and $\xi=5 \%$ critical damping ratio. The output is the time-history chart of displacements at the ground-level nodes that, will later be used to assess the influence of vibrations with the help of SWD scales [2].

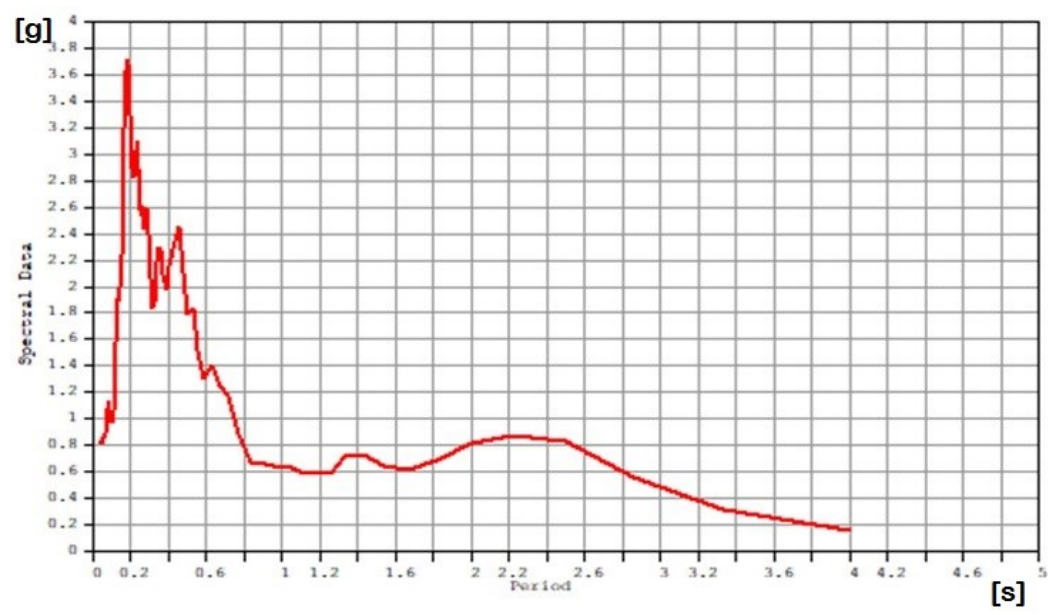

Fig. 1. The acceleration response spectrum (g) collected from the Gulf of Aquaba earthquake $[3]$.

Figure 2 presents the finite element model of a structure fixed to the ground with kinematic boundary conditions located at the bottom of the structure. The arrow shows the direction of the response spectrum calculations. The structural walls are made out of stone masonry blocks. Thickness of main load bearing walls is $51 \mathrm{~cm}$ and the partition walls $25 \mathrm{~cm}$. Slabs inside the building are constructed on steel sections, with filling in between, similarly to Klein slabs. There are two sets of staircases inside the building. One of them is located in kitchen area and goes from the building's zero level up to the last floor, it is made of concrete. The other one is made out of wood, starts in the building's basement and ends at the last floor like the concrete one [4]. 


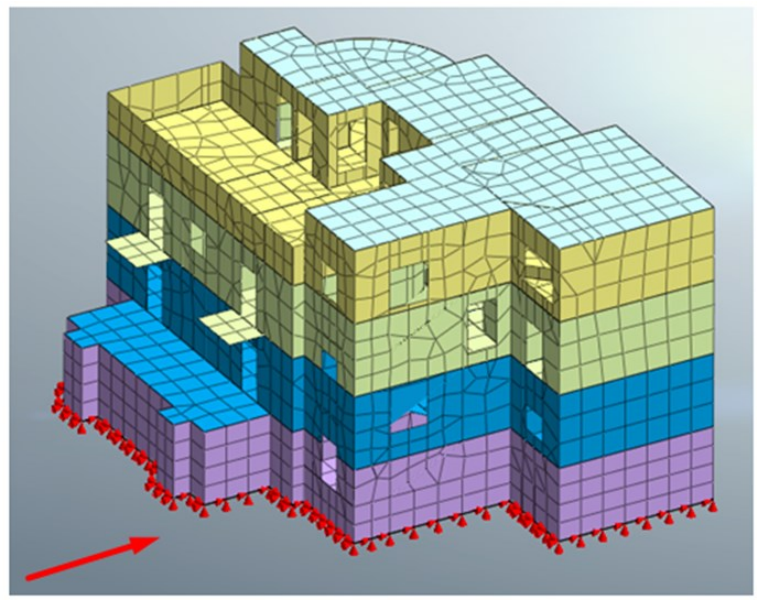

Fig. 2. The finite element model of a structure with mesh and kinematic boundary conditions.

The area of Heliopolis lies in the alluvial plain of the portion in Nile valley. The soil profile is mainly made out of a fill layer ranging somewhere from 2 to 4 meters in thickness. It is followed by the upper layer of sand that, varies from dense to very dense silty sand. Underneath, there is a middle sand layer of a thickness up to 10 meters. Beneath the middle sand is a 1.5 to 4 meter layer of densely packed silty clay. The lowest layer consists of very dense gravely sand that extends down to bedrock. The ground conditions in the vicinity of the building may vary from those given by geological surveys, as the drilling operations may have caused additional settlement of upper soil layers. The tunnel liner is composed out of half meter thick reinforced concrete segments. Tracks are laid on concrete filling with the thickness up to 3 meters. Diameter of the tunnel measuring on the outside of a liner is 9.1 meter [5]. Figure 3 presents a cross-section view to the finite element model of a metro tunnel and the structure and the subsoil. The subsoil parameters are collected in Table 1.

Table 1 Soil properties in central Cairo assumed for Al-Ahram metro station

\begin{tabular}{|l|c|c|c|c|c|}
\hline Parameter & Fill & Upper Sand & Middle Sand & Silty Clay & Lower Sand \\
\hline Thickness [m] & 3.0 & 5.0 & 8.0 & 3.0 & 21.0 \\
\hline Young modulus [MPa] & 4 & 45 & 70 & 31 & 105 \\
\hline Poisson's ratio [-] & 0.3 & 0.3 & 0.3 & 0.35 & 0.3 \\
\hline Cohesion [kPa] & 0 & 0 & 0 & 20 & 0 \\
\hline Internal friction angle & 27 & 36 & 38 & 29 & 38 \\
\hline Unit weight [kN/m $\left.{ }^{3}\right]$ & 17 & 19 & 19.5 & 18 & 19.5 \\
\hline
\end{tabular}




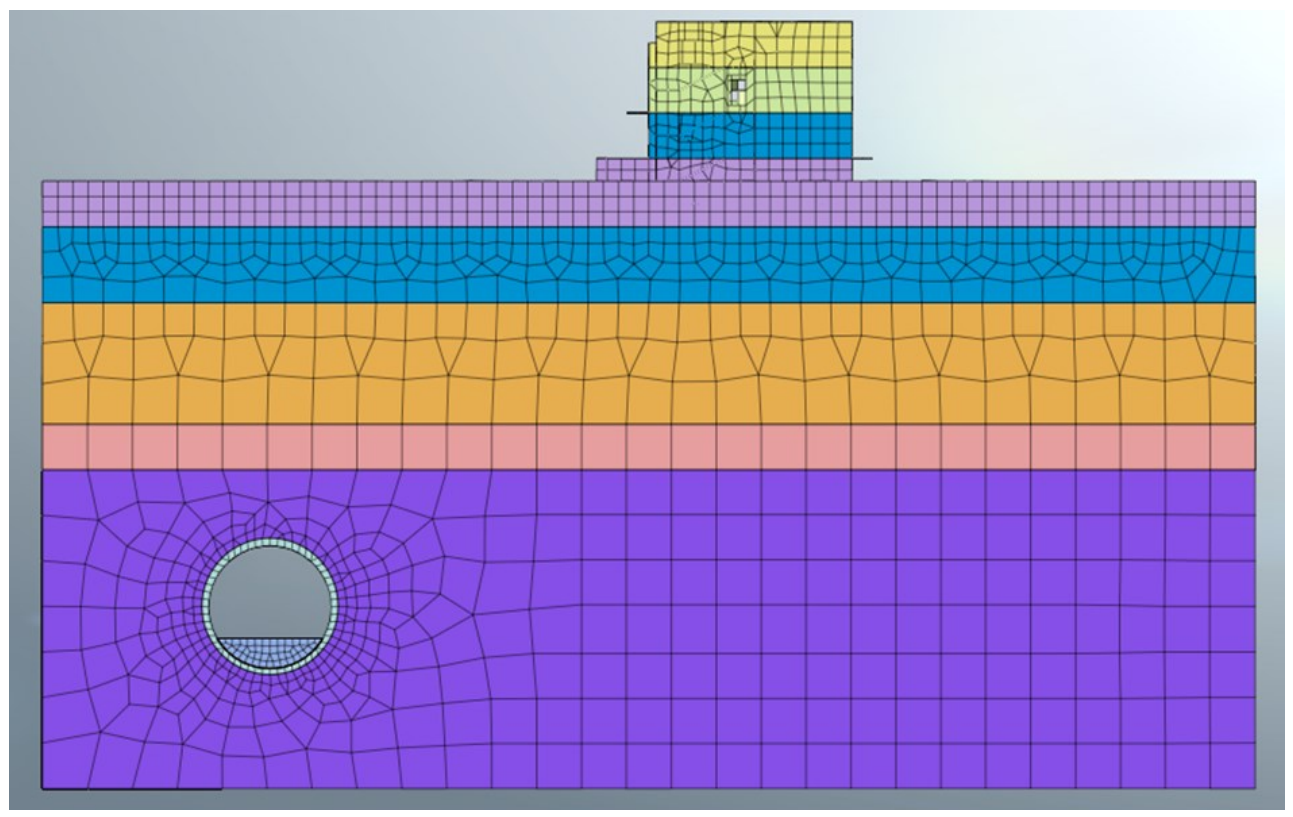

Fig. 3. A view to the finite element model of a metro tunnel and the structure and the subsoil.

\section{Numerical results}

In this study, finite element model used to predict the influence of the metro line is prepared by Midas Gen and Midas GTS NX software. Main geometry of a building along with appropriate meshes have been created in Midas Gen. The mesh and properties are then transferred for analysis to Midas GTS NX. Structure consists of five separate mesh sets to allow for convenience in reading results, as those meshes can later be hidden or shown separately. Those are consecutively: Floor -1 , Floor 0, Floor +1 , Floor +2 and the Flat Roof. All building elements in the model are created as shell elements. Even though the slabs in reality are steel beams, due to limited data, they were modelled as shells with the smeared properties of a composite. In order to increase the stability of the wooden staircase, additional steel sections are added at the edges of panels. Meshing is made as hybrid, rectangular-dominant with element size up to 1 meter. The building mesh is then transferred do Midas GTS NX and connected with soil. To assure adequate connection of both meshes, contact pairs at the overlapping faces are assumed. Soil is modelled as a box solid of dimensions $80 \times 80$ meters in $\mathrm{X}$ and $\mathrm{Y}$ directions and 40 meters in $\mathrm{Z}$ direction. The assumed thickness of consecutive soil layers is as follows: fill $-3 \mathrm{~m}$, upper sand $-5 \mathrm{~m}$, middle sand $-8 \mathrm{~m}$, silty clay $-3 \mathrm{~m}$, lower sand $-21 \mathrm{~m}$ with their properties as shown in Table 1. Hexa-dominant hybrid meshing is applied with mesh size of 3 meters for lower layers, reducing to $2 \mathrm{~m}$ and then $1 \mathrm{~m}$ for upper-most layer. The tunnel is split into two separate mesh sets connected with a contact pair, mesh size for both was set as 0.5 meter. Boundary conditions for the model are set as pinned supports at all nodes in three of the soil box faces. 
There are two types of loads applied to the model, one of them is the response spectrum load from data collected during the Gulf of Aquaba earthquake, the other one is the quasistatic load from the passage of a metro inside the tunnel.

\subsection{Response spectrum analysis}

The Gulf of Aqaba earthquake took place on November 22, 1995 at 04:15 UTC and registered 7.3 on the Mw scale, it occurred along the Dead Sea Transform fault system and affected Egypt, Israel, Jordan and Saudi Arabia. Epicenter was located at the central part of the gulf, around $300 \mathrm{~km}$ from Cairo.
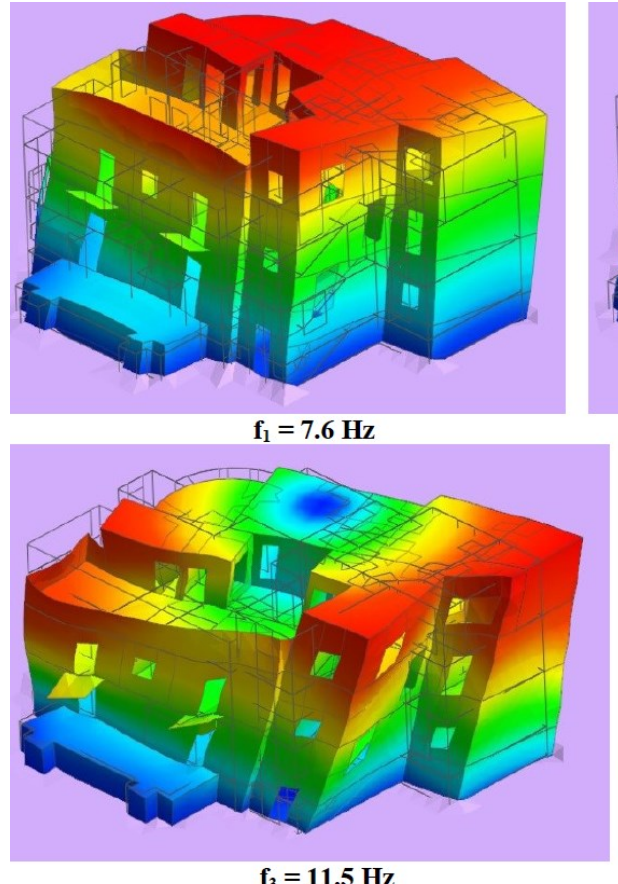

$\mathrm{f}_{3}=11.5 \mathrm{~Hz}$

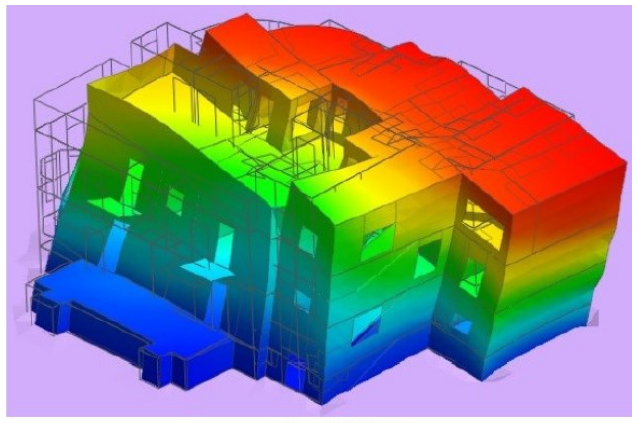

$\mathrm{f}_{2}=9.3 \mathrm{~Hz}$

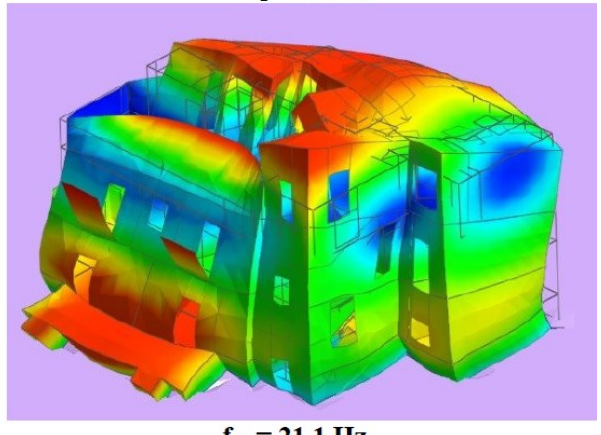

$f_{11}=21.1 \mathrm{~Hz}$

Fig. 4. Eigenfrequences and global eigenmodes of the analysed structure.

For checking of natural frequency (eigenfrequencies) of a building, the model is simplified and neither the soil or the tunnel are taken into consideration in the spectral analysis case, the boundary conditions are changed to pinned supports at the bottom face of the building's mesh as shown in Figure 2. Figure 4 presents the primary four global eigenmodes taken out of 13 computed by the software. The other mostly referred to the local floor behaviour are not presented here. Figure 5 presents the value of the Tresca shear stresses computed for the modal combination of the acceleration response spectrum. The maximum stress do not exceed $600 \mathrm{kPa}$. Although, there are some cracks visible in the building, the effects of that earthquake are not harmful for the analysed structure. 


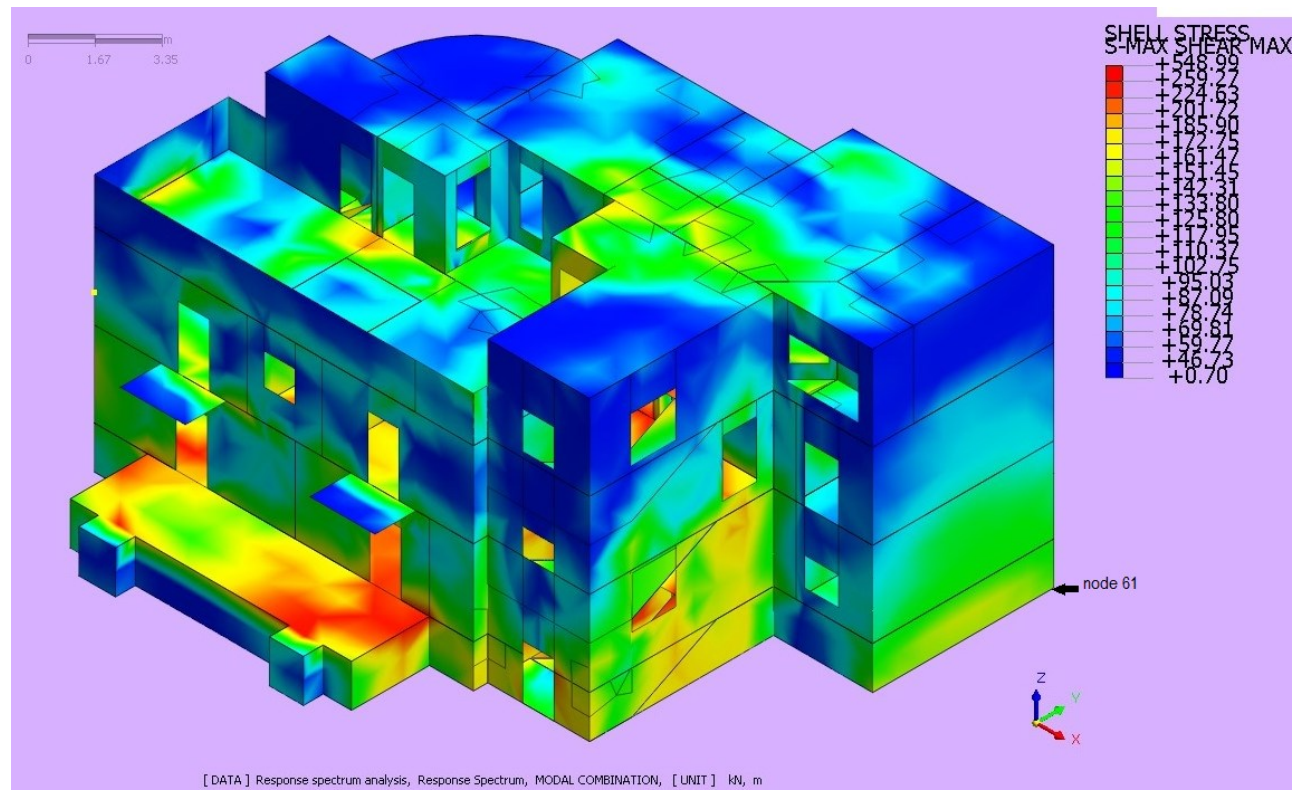

Fig. 5. Tresca shear stresses as for the modal combination of the response spectrum analysis.

\subsection{Direct integration of the equations of motion due to train quasi-static excitation}

Midas GTS NX has a possibility to define the train dynamic vertical load table and there is already a couple of preset trains that can be chosen. As most of presets assumed axle loads almost one third higher than the admissible axle load of Siemens C2 train [6], a table that was created from scratch for the needs of analysis and the quasi-static load generated at speed of $10 \mathrm{~m} / \mathrm{s}$ and the value of $\mathrm{P}=135.0 \mathrm{kN}$ at each axle i.e. $67.5 \mathrm{kN}$ at each wheel/rail contact point as shown in figure 6. Train passage through the modeled tunnel fragment takes about 19 seconds. The time-history of quasi-static load applied to the track at a wheel/rail single point contact is also visible in figure 6 . 

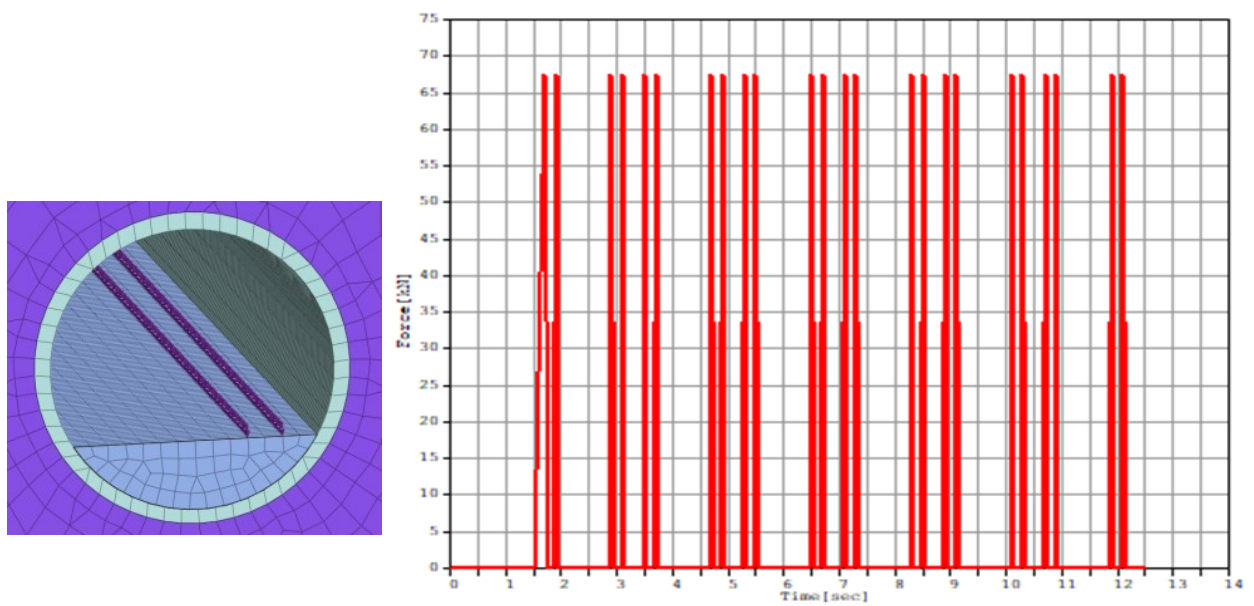

Fig. 6. The tunnel cross-section and time-history of quasi-static vertical load applied to the track at a wheel/rail single point contact of the underground train.

Figure 7 presents the time-history of the horizontal accelerations in the direction perpendicular to the metro tunnel as computed for node 61 (Fig. 5), which lies in lower corner of the building, which a stiff point at the bottom of the structure. Figure 8 presents the frequency content of the acceleration time-history as computed for node 61 . The frequency content is compared to the Ciesielski SWD - II scale, as it is provided by $\mathrm{PN}-85 / \mathrm{B}-02170$ code.

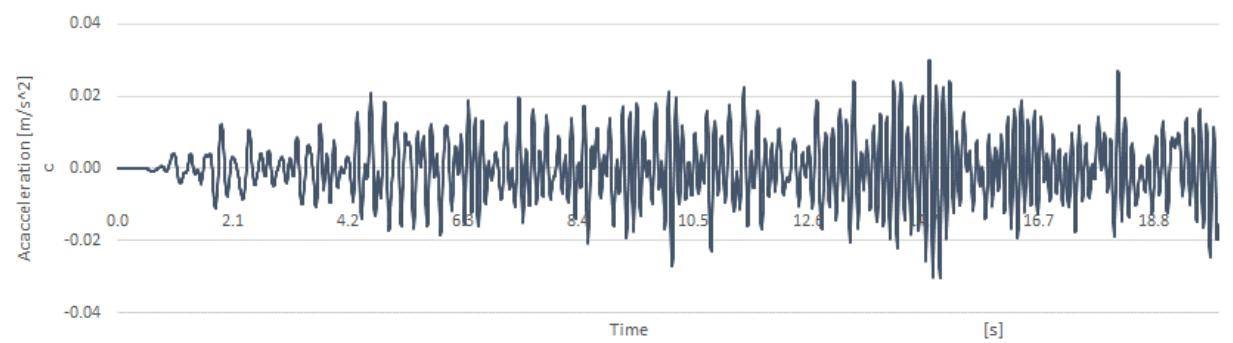

Fig. 7. Time-history of the horizontal accelerations as computed for node 61. 


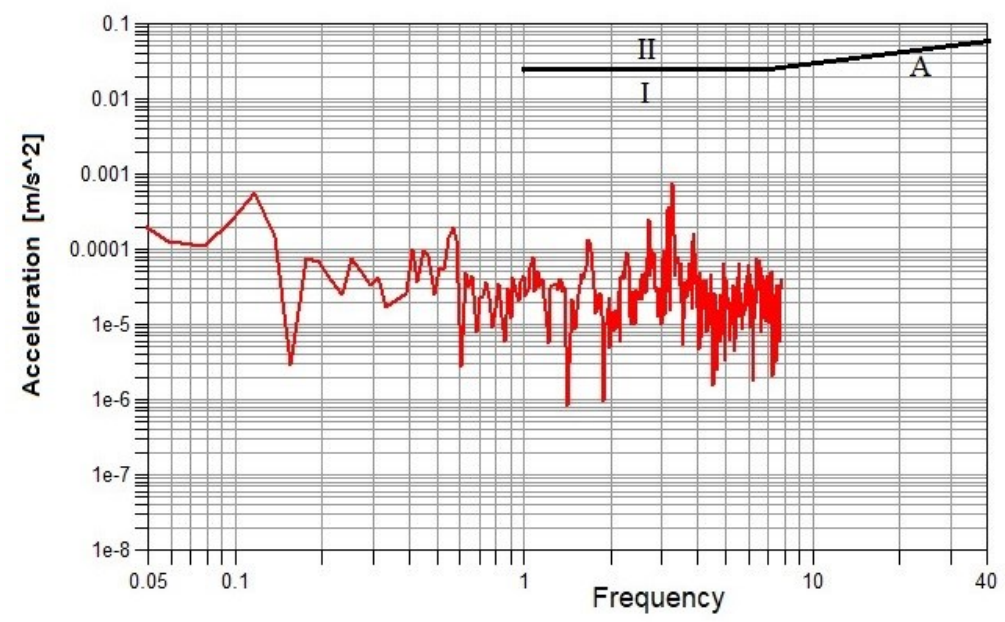

Fig. 8. Frequency content of the horizontal acceleration with the comparison to the Ciesielski scale diagram as computed for node 61 .

\subsection{Discussion}

It is observed that the displacements and accelerations created under train load are sufficiently small to place the building in zone I of the SWD-II scale. Additional stresses in masonry elements do not exceed their assumed shear strength. Due to insufficient data, an exact strength could not be determined, but with obtained values of stresses, even with drastic differences of assumed and real strength, the increase should not be significant, although if the building will be subjected to another earthquake similar to Gulf of Aquaba or Cairo earthquakes, accumulating damage may lead to destruction of the bearing walls.

Taking into consideration all data obtained, excitation from metro is not significant to the building, let alone pose any danger to humans or building elements. Existing cracks that appeared during nearby construction works and driving of diaphragm walls are not expected to propagate further under such loading. To make sure that is the case, glass seals are placed at the location of cracks to allow for width control and to eliminate the risk of further sudden damage to the building.

\section{Final remarks}

The paper presented a numerical model of the tunnel and soil and the structure interaction problem. As input, the acceleration response spectrum computed for the Gulf of Aquaba earthquake is used, as well as the quasi-static axle loading of typical metro carts. The output is shown as the time-history response of the ground-level nodes that will later be used to assess the influence of vibrations with the help of Ciesielski (SWD) scales. It is observed that the vibrations created under train load are sufficiently small and not hazardous to the structure. Additional stresses in masonry are the fraction of the shear strength. However, existing cracks that appeared during nearby construction works are not expected to further propagation under such loading. 


\section{References}

1. A.W. Sadek, A. Solaiman, and M.A. Baraka (2000). GIS-based earthquake damage analysis in the Greater Cairo area, The 12th World Conference on Earthquake Engineering.

2. PN-85/B-02170, 1985. Ocena szkodliwości drgań przekazywanych przez podłoże na budynki.

3. http://www.isesd.hi.is/ESD_Local/Database/Database1.asp

4. J.P. Kogut (2012). Opinia dotyczaca nieruchomości 14 Nazih Khalifa (d. Baron Empain), Heliopolis oraz wplywu prowadzonych $w$ jej otoczeniu prac budowlanych i montażowych a także późniejszej eksploatacji metra $w$ sasiedztwie w/w nieruchomości, Internal Report to Polish Centre of Mediterranean Archaeology, University of Warsaw, Cairo.

5. S.A. Mazek, H.A. Almannaei (2013). Finite element model of Cairo metro tunnel- Line 3 performance, Ain Shams Engineering Journal 4(4), pp. 711-712

6. https://assets.new.siemens.com/siemens/assets/public.1487593509.c1aaf5c73253d0f3332363323 6bc3c12b8a9c9b0.metro-munich-us-brochure.pdf 